\section{ambient \\ SCIENCE \\ Vol. 06h(1):16-20 \\ Year 2019}

\title{
Assessment of Self-report on Sexual Life of Married Reproductive-age Women in Iran
}

\author{
Farideh Mogharab', Nader Sharifi ${ }^{3}$, Shiva \\ Bigizadeh ${ }^{3}$, Fatmeh Honarmand \\ Jahromy',Safieh Jamali' \\ 'Department of Gynecology \& Obstetrics. University of Medical \\ Sciences, Jahrom Iran \\ ${ }^{2}$ Department of Nursing and Midwifery, Jahrom University of \\ Medical Sciences, Jahrom, Iran \\ ${ }^{3}$ Research center for Social Determinants of Health, Jahrom \\ University of Medical Sciences, Jahrom, Iran \\ Study Area: Jahrom, Iran \\ Coordinates: $28^{\circ} 30^{\prime}{ }^{\circ} " \mathrm{~N} 53^{\circ} 33^{\prime} 38^{\prime \prime} \mathrm{E}$
}

Keywords: Natural sex, Non-vaginal sex

This project was approved by the Jahrom University of Medical Sciences with ethics code No. IR.JUMS.REC.1394.208

\section{Introduction:}

The various sexual behaviors and complex interaction are several factors to cogitate on it (Oksuz \& Malhan, 2006). Various factors are effective on the sexual involvement of women; such as physiology, motives, experiences, beliefs, lifestyle, and proper relationships. If any of it not lying proper, it can have a negative effect on the sexual function and consequently the marital relations of the couple. Sometimes, the dissatisfactions unexpressed at the presence of sexual dysfunctions and can cause the strain on the relationship between the couple even resultant to divorce (Lauman et al., 1999). The sexual dysfunction is one of the most prevalent problems which affects considerably the individuals' self- confidence and quality of life and is one of the reasons for emotional tensions and marital disbalance. The past studies have revealed that the level of prevalence of sexual dysfunction among the women was 2563 percent (Ali et al., 2009). Lewis et al., (2004) revealed that 20-30 percent of men and 40-45 percent of the women have a problem at least at one of the stages of their sexual answer cycle. The international conference on population and development at Cairo in theyear 1999 considered access to the highest standard of information and sexual health as the right of all the human beings. Also, training the proper principles of the sexual activity and checking the sexual

\section{Abstract}

The present study aims to investigate the sexual function and behaviors of married reproductive- age women following a cross-sectional research done on 397 women referred to the clinics of health centers of Medical Science University of Jahrom. The average age of women was $30.94 \pm 7.01$. The data collection was done by the conventional method using the Female Sexual Function Index questionnaire. The vaginal sex was the most prevalent kind of sex among women, whereas $35 \%$ and $27.5 \%$ of the women experienced oral and anal sex, respectively. In a comparison of domains of sexual function between two groups who experienced vaginal and non-vaginal sex, there was no meaningful statistic relationship between them. There was a statistical relationship between the request for non-vaginal sexual behaviors and their acceptance by the women. About $75.3 \%$ of the women were having sexual dysfunction. The most prevalent dysfunction was related to the lack of orgasm (72.3\%) which is very high. The proper strategy is required for Iranian women to get rid of it.

difficulties of the couples are of the fundamental and standard elements of the health cares (Andrews, 2005).

The sexual behavior in human is not just a physiologic answer or a mental behavior, but it is a combination of both phenomena (Ghavam \& Tasbih Sazan, 2008). The sexual behaviors and attitudes are teachable, however, the similar sexual behaviors can have different meanings for different individuals and even it may be changed for a person from time to time (Lee, 2002). The sexual behaviors are shown for the purpose of attracting and satisfying the sexual partner, having sexual relation, demonstrating the emotions and the intercourse (Okazaki, 2002). Most of the difficulties in the sexual relations are related to the number of intercourses, time of sexual satisfaction and its quality, because each of these cases associates special symbolic meanings. Even, arrogance plays an important role in sexual relations, as the woman and man's attitude toward their own physical and sexual nature affect their sexual behavior (Mehrabi Zadeh et al., 2013). The normal sexual relation through the vagina is the most prevalent kind of sexual behaviors in the human being (Okazaki, 2002). Of course, in addition to the vaginal intercourse, there exist the other sexual behaviors such as the masturbation, molestation and so forth (Tarvrdy, 2004). The social, ethnic, and cultural factors affect the conception of society

*Corresponding Author: Safieh_jamali@yahoo.com 
and individual from the sexual attitudes and behaviors and with regard to this matter that the sexual function and attitude is a part of the women's health. Furthermore, because of being a taboo of the sexual issues in our country and also the cultural and social impediments, few studies have been done in this regard which is insufficient for the proper knowledge. Thus with regard to the role of the woman and her health and its effect on the family function and ultimately the society, a systematic study in this regard is necessary.

In an earlier study on women of reproductive age, the impact of female sexual function on their quality of life revealed that sexual function was positively correlated with all aspects of QoL, i.e., satisfaction with sexual function rises by increasing the dimensions of QoL (Jamali et al., 2018). Considering the impact of sexual function on women's lives, the aim of this study was to examine the sexual function of women and their sexual behaviours, and ultimately to compare their sexual performance between the two groups of women with natural and abnormal sexual behaviors.

\section{Methodology:}

We did a cross-sectional study on 397 women belongs tor749 year old, referred to the clinics of health centers of Medical Science University of Jahrom in the year 2018. The sampling was done by the conventional method following the selection factors; viz., un-pregnant women not suffering from any chronic diseases (diabetes and chronic blood pressure etc.), non-existence of stressful events (relatives' death and divorce) in the past six months. The tool for collecting data was a questionnaire with three parts. The first part included the demographic information (age, job, consort's job, education, life place, marriage duration), the second part was Female Sexual Function Index questionnaire and the third part for knowing the sexual behaviors of individuals and their partners. After explaining the objectives of our study and assuring the individuals about keeping the information secret, the letter of agreement was taken consciously; and after the completion, the questionnaires were registered in SPSS software. The Female Sexual Function Index questionnaire was applied for evaluating sexual function. In a research, its validity and reliability were studied by Rozen et al. (2000); Fakhri et al (2012) in Iran was verif ied.

This questionnaire included 19 questions for studying the individuals' sexual function at 6 domains, sexual desire with two questions 1 and 2, stimulation with questions 3, 4, 5 and 6, lubrication with questions 7, 8, 9 and 10, orgasm with questions 11, 12 and 13, satisfaction with questions 14, 15 and 16 , and the pain with questions 17,18 and 19. For the domains of questions 2, 3 and 4, the factor coeff icients o.6, 0.4 and 0.3 would be applied, respectively. Finally, the score of every domain was obtained from the sum of questions of that domain multiplied by its factor coeff icient. Ultimately,

the total score of sexual function was obtained from the sum of all the domains and the scale was between 2-36. The cut- off point of this questionnaire is 26.5 that the score less than 26.5 indicate of the sexual dysfunction (Rosen et al., 2000).

The cut-off scores to determine the presence of difficulties on the six domains of the FSFI were obtained from published sources (Abdo et al., 2004; Sidi et al., 2007; Song et al., 2008). Accordingly, the scores less than 4.28 in the desire domain, less than 5.08 in the arousal domain, less than 5.45 in the lubrication domain, less than 5.05 in the orgasm domain, less than 5.04 in the satisfaction domain, and less than 5.51 in the pain domain were used to classify the participants having difficulties in that particular domain.

Statistical analysis: all the data were analyzed by the use of SPSS 21. The descriptive statistic (frequency, percentage, average and standard deviation) was used for describing the demographic information. The Student's T-test was applied for comparing the women with usual sexual behaviors with the women with unusual behaviors, and Spearman and Pearson's correlation coeff icients were used for the relation among the variables and $\mathrm{p}<0.05$ was regarded as the level of significance.

\section{Results:}

Socio-demographic characteristics: the average age of women was 30.94 \pm 7.01 . Most of the women $(83.4 \%)$ were from urban regions and $72 \%$ of which were housewife and $38.3 \%$ of them had higher education (Table-1).

Female Sexual Behavior: about $90.7 \%$ of the women express that they married and satisfied, whereas $59.4 \%$ of them had total satisfaction with their first sex. A higher percentage of women (88.2\%) expressed that their husbands are faithful to them and have no extramarital relationship. Most of the women (59.4\%) expressed having sexual relations two times a week (Fig.-1). About 18.9\% of the participants mentioned that they don't have a separate bedroom and 30\% of them mentioned that their husbands always have been the beginner of sexual relation (Fig.-2).

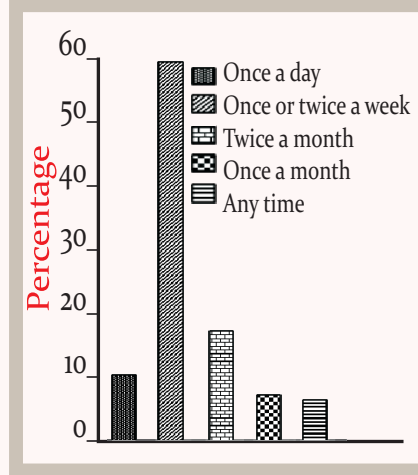

Figure-1: Frequency of intercourses in the participants

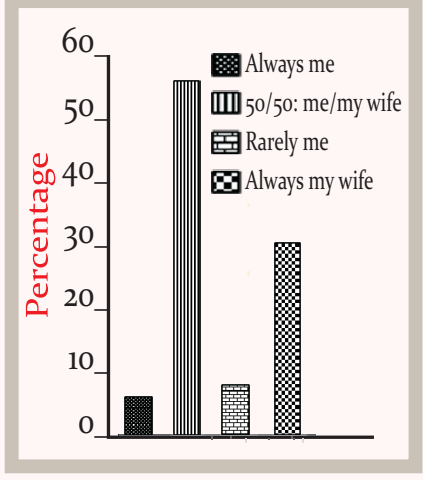

Figure-2: Ratio of sexual initiation among the participants 
Table I. Demographic characteristics of the participants $(n=397)$

\begin{tabular}{ll}
\hline Parameters & Mean \pm SD / N(\%) \\
\hline Woman's age & $30.94 \pm 7.01$ \\
Duration of marriage & $10.47 \pm 8.28$ \\
Age difference between the couples & $5 \cdot 55 \pm 3.80$ \\
Age of marriage & $20.32 \pm 4.51$ \\
Age of menarche & $13.33 \pm 2.24$ \\
Age of the first intercourse & $20.66 \pm .17$ \\
Categories of variables & \\
Educational level & \\
Uneducated & $6(1.5)$ \\
Primary school & $97(24.4)$ \\
Secondary school & $141(35.5)$ \\
Academic & $153(38.6)$ \\
Employment status & \\
Housewife & $286(72)$ \\
Employed & $111(28)$ \\
Husband's Education & \\
None & $4(1)$ \\
Primary school & $126(31.7)$ \\
High school & $152(38.3)$ \\
Academic & $115(29)$ \\
Husband's Occupation & \\
Employed & $81(20.4)$ \\
Non-employed & $298(79.6)$ \\
No. Smoking history $(\%)$ & $29(7.3)$ \\
Yes & $368(92.7)$ \\
No & $294(78)$ \\
Yes & $83(22)$ \\
No & $66(16.6)$ \\
Rural & $331(83.4)$ \\
\hline Urban & \\
\hline
\end{tabular}

About $59.7 \%$ of them have sex with total satisfaction. In reply to this question, whether your husband has had sex with you, while you were sleeping? About 31.7\% answered " yes". Our results revealed that $35.1 \%$ and $27.5 \%$ of the women experienced oral and rectal sex, respectively; while most of them (97\%) were habituated of vaginal sex.

Our results revealed that $36.5 \%$ of men asked for the anal sex that $27.5 \%$ of women reacted positively to their request that there was a positive and meaningful relationship between the request and acceptance of this relation ( $\mathrm{p}<0.0001, \mathrm{r}=0.76$ ); despite the fact that $75.9 \%$ of them hate this relation. Furthermore, $40.6 \%$ of men asked for the oral sex while $36.8 \%$ of the women reacted positively to their request. The statistic results showed that there has been a positive and meaningful relationship between the request and acceptance of this relation ( $\mathrm{p}<0.0001, \mathrm{r}=0.78)$. Interestingly, $42 \%$ of women expressed that they react positively to their husbands' request because of their interest in their husbands.

A total of $71.3 \%$ of women expressed that the behaviors such as a request for the unusual sexual relation without satisfaction, applying threat and violence for having the unusual sexual relations and so forth are regarded the violence against women. About $39.8 \%$ and $20.9 \%$ of the women reported the pain during intercourse and vaginal putrefaction respectively as the kind of damage they experienced in the sex. Also, in reply to this question that what is your opinion about marital sexual relations in general? Surprisingly, only $45.8 \%$ of the participants expressed that they enjoy this relation.

Female sexual function: in our study of the sexual function of the women surveyed, the least score on orgasm (3.3184 \pm 1.13$)$ and the score in the lubrication, stimulation, satisfaction, and pain during intercourse was reported $3.57 \pm 1.13,3.69 \pm 1.26,4.12 \pm 1.06$ and $4.37 \pm 0.91$, respectively. A total of $74.1 \%$ of the women mentioned that they did not have a tendency to have sex during the past one month; $74.1 \%$ of the women have sexual stimulation during the sex for a little time, $89 \%$ of the women did not have lubrication during the sex and $61.2 \%$ of them dissatisfied totally with the sexual relations during the past one month, and $63.7 \%$ of them always experienced pain during the intercourse.

According to the cut- off point, $75.3 \%$ of the women had sexual dysfunction. Also, the prevalence of dysfunction on each of sexual function domains, sexual desire, sexual stimulation, lubrication, orgasm, satisfaction and pain during intercourse was 224 (56.4), 247 (62.2), 287 (72.3), 228 (72.5), 188 (47.4), and 158 (39.8). The prevalence of dysfunction of sexual domains is presented in Table-2.

The results obtained from the table 3 reveal that there was no meaningful difference between the average of score of sexual function and most of its domains (desire, stimulation, lubrication, orgasm, dyspareunia) in the women who experienced oral and rectal sex and the women who had vaginal sex ( $p>0.05)$; except on the domain of satisfaction, it was revealed that the women with unusual sexual behaviors have less sexual satisfaction $(\mathrm{p}<0.05)$.

Table-2: The prevalence of sexual problems in women $(n=397)$

\begin{tabular}{lll}
\hline Domain & Sexual dysfunction & Normal sexual function \\
\hline Desire & $224(56.4)$ & $173(43.6)$ \\
Arousal & $247(62.2)$ & $150(37.8)$ \\
Lubrication & $287(72.3)$ & $110(27.7)$ \\
Orgasm & $288(72.5)$ & $109(27.5)$ \\
Satisfaction & $188(47.4)$ & $209(52.6)$ \\
Pain & $158(39.8)$ & $239(60.2)$ \\
Total Score & $298(75.3)$ & $99(24.7)$ \\
\hline
\end{tabular}

Table 3: Sexual function domains scores in women with and without Abnormal sexual behavior $($ Mean \pm SD)

\begin{tabular}{llll} 
Sexual function & \multicolumn{2}{l}{ WAnSB $(\mathrm{n}=145)$ WNSB $(\mathrm{n}=249)$} & $\mathrm{p}$-value* \\
\hline Libido & $4.20 \pm 1.00$ & $4.03 \pm 1.06$ & 0.11 \\
Sexual arousal & $3.80 \pm 1.26$ & $3.62 \pm 1.26$ & 0.18 \\
Orgasm & $3.35 \pm 1.31$ & $3.28 \pm 1.30$ & 0.6 \\
Lubrication & $3.44 \pm 1.10$ & $3.63 \pm 1.14$ & 0.10 \\
Sexual satisfaction & $3.96 \pm 1.10$ & $4.20 \pm 1.04$ & 0.03 \\
Pain & $4.45 \pm 0.86$ & $4.32 \pm 0.94$ & 0.20 \\
\multicolumn{2}{l}{ Total sexual function $\mathbf{2 3 . 2 2} \pm 3.31$} & $\mathbf{2 3 . 1 0} \pm 3.54$ & $\mathbf{0 . 7 5}$ \\
\hline
\end{tabular}




\section{ORIGINAL ARTICLE}

WAnSB- women Abnormal sexual behavior; WNSB- women Normal sexual behavior; *-'Student's t test.

\section{Discussion:}

Our study investigated for the first time the sexual function and sexual behaviors in married reproductive-age women in Iran. The findings revealed that none of the women experienced the sexual relation before the marriage and they did not have homosexual relation, too. The homosexuality is an obscene sexual relation in the Iranian culture and society and it is illegitimate in Islam religion. Though all of our participants were Muslim and obligated to the religion and rules; so, this affair had been inconsiderable and expressed about zero percent. On one side, the sexual relation in an Iranian society always is done in the marital condition, and with regard to the importance of marriage to a virgin wife in the Iranian culture, this matter was also reported inconsiderable in the studies (Farahani et al., 2011; Heshemi et al., 2013).

Straight sex was the most prevalent kind of sex in the women participants. The oral and rectal sexes were not popular and common among the women; the prevalence of oral and rectal sexes in our study. However our results revealed a little higher score as compared to the earlier study (Liu et al., 1998; Avasthi et al., 2008. The study done by Henzel et al. (2008) on 387 youth women revealed the prevalence of anal and oral sex was $65 \%$ and $13 \%$, respectively. On the other side, Mosher et al. (2005) reported that the prevalence of anal and oral sex among the age group of $15-45$ years old in America was 35\% and 88\%, respectively. But, Gindi et al. (2008) found the prevalence of oral sex and rectal sex was $16 \%$ and $6 \%$, respectively in the girls of 12-25years old of America. For expressing the reason of being different of these statistics at different societies, it could be hypothesized that the men and women are trained with different attitudes, beliefs, and situations due $t$ which their function and attitude toward the sex are different and the different results are expressed in the results of studying the different societies.

The opinion of the participated women on oral and anal sex were found to obey our religious (Islamic) and also the civil rules of Iran. The women accept this relationship despite their own desire only due to the fear of not-being faithful to them and turning to the sexual relations outside the home, fear of misconduct and violence with them and divorce and on the other side, maintaining family cohesion and fidelity to it can be of the reasons of acceptance of the unusual sexual relations (Shirpak et al., 2008).

Further, just on the domain of satisfaction, the women who experienced the unusual sexual behaviors (anal and oral sexes) expressed lower level of satisfaction. The past researches in regard of comparison of the sexual behaviors are limited and no study was found. Also, with regard to the percentage obtained from the study of non-vaginal sexual behaviors, the need to the correct education of sexual issues
Ambient Science, 2019: Vol. 06h(1); 16-20 DOI:10.21276/ambi.2019.06h.1.oa03

and skills and the sexual consulting specially with the consort is felt necessary. On the other side, informing the couples about the consequences of unusual behaviors such as the increase of risks of putrefactions like AIDS and genitourinary infections and also the irreparable physical and mental damages are necessary and important in the reduction of non-vaginal behaviors.

The prevalence of sexual dysfunction in the women were seen to be very high which is coincide with the result of Jamali et al. (2014) conducted on Iran's women but not to Rosen et al. (2000) which reported only about 30.5\%; Jaafarpour et al. (2013) in Iran reported $42.6 \%$ (sexual dysfunction) and $42.3 \%$ (orgasmic dysfunction); Abdo et al. (2004) on Brazil women reported 49\% (sexual dysfunction) and 21\% (orgasmic dysfunction). However, in a Malaysian study, the sexual dysfunction and orgasmic dysfunction were expressed as $62.9 \%$ and $59.1 \%$, respectively (Sidi et al., 2001) and it was reported as $43.1 \%$ in Korean women (Song et al., 2008). In Turkey, this dysfunction was $48.3 \%$ among women and $42.7 \%$ in the domain of orgasm (Oksuz \& Malhan, 2006). It is specif ied that the sexual dysfunction varies in women living in various societies and the continuation of sexual dysfunction even confronts the family with serious physical-mental trauma.

\section{Conclusion:}

The sexual dysfunction is always found in the women. On one side, the amount of non-vaginal sexual behaviors is disputable; on the other side, the sexual dissatisfaction in the non-vaginal relations demonstrates the couples' need to the education of sexual issues and consulting.

\section{Strengths and weaknesses of the study}

$\star$ Of the restrictions of this research, it can be referred to the non- evaluation of the emotional and mental status of the participants that are effective on the marital relations and satisfaction.

$\star$ The reason is the cultural and religious restrictions in the society of Iran that the individuals can't speak easily about their sexual issues. Perhaps some individuals were not truthful in the explicit expression of their issues.

$\star$ In this research, the women referred to the governmental centers were studied and it is possible that the findings were not indicative of all the population studied.

$\star$ The explanation of the questions to the participants and taking correct answers from them needs to spend considerable time. Yet, because it was the first time that these issues were expressed with them, their answers were true and completely reliable.

$\star$ The use of a tool of Female Sexual Function Index questionnaire (FSFI) and its comprehensiveness that includes all the key dimensions of the sexual function; and being at a high level of reliability and validity are the fortes of present study that has been applied in a few studies in Iran.

Acknowledgment:

Authors acknowledge all the participants who unhesitatingly participated in this study. 


\section{References:}

Abdo, C.H., Oliveira, W.M. Jr., Moreira, E.D. Jr. \& Fittipaldi, J.A. (2004): Prevalence of sexual dysfunctions and correlated conditions in a sample of Brazilian women - results of the Brazilian Study On Sexual Behavior (BSSB). Int. J. Impot. Res., 16(2):16o-166.

Ali, R.M.A., Al Hajeri, R.M., Khader, Y.S. \& Ajlouni, K.M. (2009): Factor associated with sexual dysfunction in Jordanian woman and their sexual attitudes. Ann. Saudi Med., 29(4): 270-274.

Andrews, G. (2005): Womens Sexual Health. 3rd ed. Pub. by: Bailièrre Tindall, Edinburgh: 622 pp.

Avasthi, A., Kaur, R., Prakash, O., Banerjee, A., Kumar, L. \& Kulhara, P. (2008): Sexual Behavior of Married Young Women: A Preliminary Study from North India. Indian J. Community Med., 33(3):163-167.

Fakhri, A., Pakpour, A.H., Burri, A., Morshedi, H. \& Zeidi, I.M. (2012): The Female Sexual Function Index: translation and validation of an Iranian version. L. Sex Med., 9(2):514-523.

Farahani, F.K., Cleland, J. \& Mehryar, A.H. (2011): Associations between family factors and premarital heterosexual relationships among female college students in Tehran. $\underline{I n t}$. Perspect. Sex Reprod. Health, 37(1):30-39.

Ghavam, M. \& Tasbih Sazan, R. (2008): Prevalence and diversity of sexual disorders among male and female patients in a family health care clinic, Tehran-Iran. I. Urmia Univ. Med. Sci., $18(4): 634-639$.

Gindi, R.M., Ghanem, K.G. \& Erbelding, E.J. (2008): Increases in oral and anal sexual exposure among youth attending sexually transmitted diseases clinics in Baltimore, Maryland. L. Adolesc. Health, 42(3):307-308.

Hashemi, S., Seddigh, S., Tehrani, F.R., Khansari SM.H. \& Khodakarami, N. (2013): Sexual Behavior of Married Iranian Women, Attending Taleghani Public Health Center. L. Reprod. Infertil., 14(1):34-38.

Hensel, D.J., Fortenberry, J.D. \& Orr, D.P. Variations in coital and noncoital sexual repertoire among adolescent women. $L$ Adolesc, Health. 42(2):170-176.

Jaafarpour, M., Khani, A., Khajavikhan, J. \& Suhrabi, Z. (2013): Female Sexual Dysfunction: Prevalence and Risk Factors. L. Clin. Diagn. Res., 7(12):2877-288o.

Jamali, S., Inaloo, R., Javadpour, S., Haghbeen, M., Poornowrooz, N. (2018): The relationship between sexual function and quality of life in reproductive-age grouped women in Iran: a cross-sectional study. Ambient Sci., o5(Sp1):20-23
Jamali, S., Zarei, H. \& Jahromi, R.A. (2014): The relationship between body mass index and sexual function in infertile women: A cross-sectional survey. Iran J. Reprod. Med., 12(3):189-198.

Laumann, E.O., Paik, A. \& Rosen, R.C. (1999): Sexual dysfunction in the United States: prevalence and predictors. L. Am. Med. Asso., 281(6):537-544.

Lewis, R.W., Fugl-Meyer, K.S., Bosch, R., Fugl-Meyer, A.R., Laumann, E.O. \& Lizza, E. (2004): Epidemiology/risk factors of sexual dysfunction. L. Sex Med.,1(1):35-39.

Liu, H., Xie, J., Yu, W., Song, W., Gao, Z., Ma, Z. \& Detels R. (1998): A study of sexual behavior among rural residents of China. $L$. Acquir. Immune Defic. Syndr. Hum. Retrovirol., 19(1):80-88.

Mehrabi Zadeh M, Mansouri Z \& Javanmard Z. (2013): Investigating the Relationship Between Sexual Behavior Pattern and Couple Adjustment of Women Regarding to Age Adjusting Variable. J. Women and Society, 4(1).

Mosher, W.D., Chandra, A. \& Jones, J. (2005): Sexual behavior and selected health measures: men and women 15-44 years of age, United States, 2002. Adv. Data., 362:1-55.

Okazaki, O. (2002): Influences of capture on Asian American's sexuality. L.Sex Res., 39(1):34-41.

Oksuz, E. \& Malhan, S. (2006): Prevalence and risk factors for female sexual dysfunction in Turkish women. L. Urol., $175(2): 654-658$

Rosen, R., Brown, C., Heiman, J., Leiblum, S., Meston, C., Shabsigh, R., Ferguson, D. \& D'Agostino, R. Jr. (2000): Female Sexual Function Index (FSFI): A multidimensional selfreport instrument for the assessment of female sexual function.J. Sex. Marital Ther., 26(2):191-208.

Shirpak, K.R., Chinichian, M., Maticka-Tyndale, E., Ardebili, H.E., Pourreza, A. \& Ramenzankhani A. (2008): A qualitative assessment of the sex education needs of married Iranian women. Sex. Cult.: Interdisc. Quart., 12(3):133-150.

Sidi, H., Puteh, S.E., Abdullah, N. \& Midin, M. (2007): The prevalence of sexual dysfunction and potential risk factors that may impair sexual function in Malaysian women. J. Sex. Med., 4(2):311-321.

Song, S.H., Jeon, H., Kim, S.W., Paick, J.S., Son, H. (2008): The prevalence and risk factors of sexual dysfunction in young Korean women: an internet-based survey. J. Sex. Med., 5(7):1694-1701.

Tarvrdy, M. (2004): Effect of prinoraphy on the sexual satisfaction of women referred to hospitals in Tabriz. Master's thesis of midwifery, submitted in Shahid Beheshti University of Medical Sciences, Iran. 